\title{
(息)
}

Citation:

Yeo, RK and Gold, J (2015) More than meets the eye: Working around technology in cross-boundary work contexts. Information Technology and People, 28 (3). 623 - 652. ISSN 0959-3845 DOI: https://doi.org/10.1108/ITP-05-2013-0091

Link to Leeds Beckett Repository record:

https://eprints.leedsbeckett.ac.uk/id/eprint/1553/

Document Version:

Article (Accepted Version)

The aim of the Leeds Beckett Repository is to provide open access to our research, as required by funder policies and permitted by publishers and copyright law.

The Leeds Beckett repository holds a wide range of publications, each of which has been checked for copyright and the relevant embargo period has been applied by the Research Services team.

We operate on a standard take-down policy. If you are the author or publisher of an output and you would like it removed from the repository, please contact us and we will investigate on a case-by-case basis.

Each thesis in the repository has been cleared where necessary by the author for third party copyright. If you would like a thesis to be removed from the repository or believe there is an issue with copyright, please contact us on openaccess@leedsbeckett.ac.uk and we will investigate on a case-by-case basis. 


\section{More than Meets the Eye: \\ Working Around Technology in Cross-Boundary Work Contexts}

( $4^{\text {th }}$ Revision)

\section{Structured Abstract}

Purpose - This study explores how organizational actors interpret and enact technology in cross-boundary work contexts during e-government implementation in a public organization in East Malaysia.

Methodology - Case study methodology involving semi-structured interviews, unobtrusive observations, and archival records was utilized in the study. Interview subjects include management staff, general employees, and information technology (IT) specialists to provide rich descriptions of their work practice.

Findings - Three distinct contexts contribute to cross-boundary work practice in relation to IT use and non-use, namely standardization (complete IT use), hybridization (partial IT use), and conventionalization (zero IT use). Technology enactment strategies such as acceptance, avoidance, adaptation, and configuration are employed depending on actors' interpretation of technology complexity and task interdependency.

Practical Implications - Early interventions could involve examining how and why employees accept or avoid technology as part of their work practice and how they switch between enactment strategies. Organizations could ensure better team support to capitalize on the robust social interaction in cross-boundary work contexts to develop greater synergy in technology improvisations.

Originality/Value - The study extends the technology enactment perspective as it offers new meanings to structures of action by understanding the temporal agentic orientations and how these are constructed by cross-boundary work contexts. It also offers insight into how 


\begin{abstract}
enactment strategies are developed according to the productive tensions that arise from the interplay of cognitive orientations.
\end{abstract}

Keywords: Human agency, task interdependency, technology enactment, e-government implementation, cross-boundary work practice, case study 


\section{Introduction}

Over the years, technology has been the engine behind electronic government or egovernment initiatives to serve the public more efficiently. Within these initiatives, technology has been used as an intervention and organizing tool for transforming public organizations (Cordella and Iannacci, 2010). Technology therefore serves as an object and an agency in shaping human action and organizational process (Orlikowski and Barley, 2001). E-government applications exemplify the materiality of technology through objects that afford for action (Leonardi and Barley, 2010). The materiality of such objects both enables and constrains technology enactment depending on the context of use. Information systems that drive e-government applications have played a critical role in changing the way employees manage their daily tasks, social relations, and interaction with citizens (Robey and Sahay, 1996).

In e-government implementations, the role information technology (IT) is critical to the realization of organizational vision through the integration of leadership, crosscoordination, and know-how (West, 2004). In turn, public organizations will be better equipped to serve their internal and external stakeholders by adopting a comprehensive approach to service provision (Jaeger and Thompson, 2003). Studies exploring technology enactment during change interventions have focused on the use of technology in innovation (Lin, 2011) and work redesign (Volkoff et al., 2007). Also, studies exploring technology use in organizational contexts have focused on the objectivity rather than the object of technology affecting users' interpretation and enactment of technology (e.g. Boudreau and Robey, 2005; Orlikowski, 1992).

In this paper, we explore how organizational actors interpret and enact technology in their work practice. The context of this study is interesting as it involves e-government implementation in an East Malaysian public organization. Unlike similar research conducted 
in developing countries (e.g. Cordella and Iannaci, 2010, Robey and Sahay, 1996), this study presents an unusual context from which to explore cross-boundary work practice arising from a dynamic exchange of technology enactment strategies. We define technology enactment as the performance of an act on one or more functions of technology such as inputting, retrieving, or organizing data by following the protocol of a hardware and software program (Robey and Sahay, 1996). More specifically, we explore the relationship between human action and task accomplishment, particularly how actors organize meanings around their work practice through technology use (Feldman and Orlikowski, 2011).

Central to this study are the cross-boundary contexts that characterize the use of technology in e-government services in the public sector of East Malaysia. We define a boundary as a line of tasks that are performed by a certain group of employees (Levina and Vaast, 2006). Division of labor and roles for each boundary could be specialized or dynamic depending on the influence of technology on how tasks are accomplished (Kellog et al., 2006). In this study, three cross-boundary work contexts have been identified: standardization (complete IT use), conventionalization (complete manual work), and hybridization (partial IT use). Interaction of these contexts has led to different enactment strategies based on how technology is used. Complexity of technology and task interdependency both influence actors' choice of enactment strategies which in turn shape their work practice. We define technology complexity as work practice constrained by the magnitude of task interdependencies as a result of technology use (Bailey et al., 2010). Cross-boundary work practice has posed a challenge for the East Malaysian public sector in rolling out its egovernment services given its lack of IT exposure.

Globalization pressure for change has led the East Malaysian Government to embark on a reinvention strategy in 1997 by introducing e-government as a State-wide initiative to bridge the divide between government and citizens (Abdul Karim and Mohd Khalid, 2003). 
We chose a public organization in East Malaysia, known only as INFunity, for our research as it is characteristic of a forward-looking organization challenged by the entrenched behavior of inward-looking employees struggling to view the future from their past. Because of our unusual position to access the research site for an extended period, we were able to gain a deeper understanding of the way technology is interpreted and enacted based on the employees' daily work practice (Jarzabkowski, 2005). Our data led us to uncover four enactment strategies according to actors' interpretation of technology complexity: acceptance, avoidance, adaptation, and configuration. The relationship of these strategies becomes even more robust in intersections between standardization, conventionalization, and hybridization. To guide our purpose of inquiry, we developed the following research questions:

1. How organizational actors interpret the role of technology in cross-boundary work contexts during e-government implementation?

2. How do these interpretations influence their work practice resulting in different technology enactment strategies?

In this paper, we build on Orlikowski's (1996) concept of situated change in egovernment implementation and Boudreau and Robey's (2005) technology enactment as influenced by cross-boundary work practice. Through INFunity, we illustrate emergent characteristics of cognitive orientation and action taking represented in the constant negotiation of technology interpretation and enactment, offering an alternative perspective of situated practice (Orlikowski, 1996; Vaast and Walsham, 2009). We further describe how actors switch between enactment strategies using technology as an intervening tool to sustain their work practice in cross-boundary settings (Orlikowski, 2000).

This paper contributes to technology enactment literature in three ways. First, it clarifies the conceptual relationship between the interpretation and use of technology and 
how work practice is affected based on the cognitive orientation of actors in relation to their perception of task interdependency and technology complexity (c.f. Argote, 1999; Orlikowski and Iacono, 2001). Second, it extends current understanding of technology enactment by examining the interplay of cognitive orientations which creates productive tensions that shape enactment strategies in cross-boundary work contexts (c.f. Boudreau and Robey, 2005). Third, it offers insight into the relationship between roles, tasks, and tools by examining the interplay of enactment strategies which leads to direct and indirect workarounds redefining situated practice (c.f. Leonardi and Barley, 2010; Orlikowski, 1996). Taken together, these three perspectives contribute to the extant literature a further understanding of human agency, task interdependency, and technology enactment in cross-boundary work contexts (c.f. Levina and Vaast, 2006; Robey and Sahay, 1996).

\section{Role of technology in e-government contexts}

\subsection{Beyond technology in the public sector}

The success of e-government outcomes is largely attributed to the optimal use of IT to transform public service efficiency through time and cost reduction (West, 2004). However, e-government implementation is not merely about the use of IT; rather, it is about developing a different work culture that connects public organizations and citizens to a wider network of government-linked activities bringing greater convenience to citizens (Nasim and Sushil, 2010). Speed and reach are two critical considerations for any successful e-government implementation (Jaeger and Thompson, 2003). The wider the digital divide between government and citizens, the greater the challenge to gain internal and external support for IT adoption (Deng, 2008).

In developing countries, e-government implementation has proven to be challenging as both employees and customers are not exposed to the wider use of technology (Chen et al., 2007). Internally, availability of IT support and readiness of users affect how technology is 
incorporated into their work practice (Feldman and Orlikowski, 2011). Externally, customers' resistance to the use of IT has hindered the development of new e-government applications (Alomari et al., 2010). In contrast, developed countries respond faster to IT advancement leading to greater standardization of services across the public sector (Cordella and Iannacci, 2010). This study explores the challenges of e-government implementation in Malaysia where the role of technology is not fully exploited in most public organizations affecting the standardization of their e-government services.

\subsection{Reinventing government in East Malaysia}

In 1997, a Reinventing Government initiative was announced in an East Malaysian state to introduce 'e-government' as a tool for driving public-sector reform. One of the aims was to challenge the old civil service mindset by integrating technology into all aspects of work practice (Yeo, 2009). Through this initiative, a host of online services was introduced on the websites of major public organizations in East Malaysia. These services cover areas like agriculture, art, culture, leisure, education, employment, and work environment. In this study, we focus on one of the organizations, INFunity, as it offers a number of online services but constantly challenged by different levels of IT acceptance of their employees and customers.

\section{Overview of the literature}

The role of technology in work organizations has been discussed from a variety of perspectives, including IT adoption (e.g. Fang et al., 2013), strategy (e.g. Preston and Karahanna, 2009), virtual communication (e.g. Kim et al., 2012), and organizational change (e.g. Hayes, 2008). Central to this study is the relationship between human agency and technology enactment in cross-boundary work contexts (e.g. Boudreau and Robey, 2005; 
Levina and Vaast, 2006; Orlikowski, 1996, 2000). In what follows, we outline several distinct yet interrelated theoretical perspectives of the role of technology in work practice, including cognitive orientation, task interdependency, and technology enactment. Figure 1 illustrates the relationship of the conceptual themes.

\section{$====$ Take in Figure 1 near here $====$}

\subsection{Cross-boundary work practice}

The reciprocal relationship between technology use and task interdependency is particularly crucial for understanding how enactment strategies play out in cross-boundary work contexts. The role of technology could be central, peripheral, or even irrelevant to work practice in the context of standardization (complete IT use), hybridization (partial IT use), and conventionalization (zero IT use) (see Figure 2). These contexts necessitate the existence and acceptance of e-government services particularly in developing countries where technology is not widely adopted. Working across boundaries requires the understanding and coordination of context-specific tasks between task functions where IT is involved (Bechky, 2003). Because routines and operating procedures change between contexts, the structure and process of action and socialization will also change (Levitt and March, 1988).

$====$ Take in Figure 2 near here $====$

At the intersection between two or more contexts (e.g. intersection A, B, C, or D), actors will constantly need to modify their mental schemas when approaching certain tasks requiring the use or non-use of IT. Such modification affects the transitional roles of actors to approach their immediate tasks and these are related to other tasks. Consequently, their action is shaped by the way they organize cognitive and material constructs (Piszczek and Berg, 2014). For instance, when actors in intersection A are polarized by the need to completely use IT (standardization) and fall back on manual procedures (conventionalization) at the same time, their work practice will be influenced by cross-boundary interactions including task 
interdependency, role clarity, and work process (Kellog et al., 2006). In most cases, these boundary interactions are dynamic and unpredictable moving actors between routinized and improvised work practice (Marrone et al., 2007). More importantly, negotiation of specific actions is driven by actors' cognitive orientation through their perception of IT and its influence on their tasks. Perceiving IT from a short, medium, or long-term perspective will have an impact on technology enactment. Further, cross-boundary work contexts create different layers of task interdependency that ultimately affect human agency and technology enactment (Bailey et al., 2010).

\subsection{Human agency and technology use}

The use of technology in work practice has elevated its role beyond that of a tool; in fact, interpretation of technology has reached a more philosophical level with its constitutive relationship between 'hardware' (technical properties) and 'software' (agentic properties including programming and human interface) (Orlikowski and Iacono, 2001). Embedded within these properties are material and cultural aspects associated with technology that influence its design, selection, and use (Walsham, 2002). That technology is a tool, characterized by a certain 'fixedness' when used to process work, is no longer applicable in today's complex organizations (Button, 1993; Markus and Robey, 1988). Its objectivity, stability, and independence are constantly disrupted by emergent patterns of enactment due to the temporal and situated nature of work practice as well as users' curiosity with the experimentation of technology use (Boudreau and Robey, 2005; Kling and Saachi, 1982).

The above perspective reinforces the role of technology which induces temporal orientations to the structure of action during socialization (Emirbayer and Mische, 1998). These orientations, facilitated by temporally-embedded processes, could lead to intended and unintended consequences of technology use (Yates et al., 1999). The temporality occurs when actors contextualize their prior and perceived experience through a recursive process of 
iteration and projection that characterize situated practice (Brown et al., 1989; Vaast and Walsham, 2009). In doing so, they become sensitive to changes in the structures of action and the relationship between them.

Patterns of technology use are also contingent upon the social context where its role in work practice is bound by time and space (Schultze and Orlikowski, 2004). As such, the agentic aspect of technology use reinforces the possibility of how technology could be enacted by simultaneous groups of actors in a distributed manner. Such distributed enactment is influenced by actors' perception of technology's complexity and its relation to task structures (Orlikowski, 2000). However, task environments are bound by complex interdependencies between technology (tool), roles (agency), and domain (context) (Thompson, 1967). In cross-boundary work contexts, how actors perceive their roles, tasks, and tools will ultimately have an influence on their enactment strategies (Zammuto et al., 2007).

\subsection{Cognitive orientation}

Contingencies of work practice do not necessarily determine if actors will adopt a reinventive response to technology enactment (Boudreau and Robey, 2005). Rather, it is the cognitive orientation of actors - whether they adopt a projective or iterational orientation to negotiate existing practice - that determines their enactment strategies (Emirbayer and Mische, 1998). Cognitive orientation is guided by the mental schemas that actors possess of a situation based on prior and perceived experience (Weick, 1998). If a schema is incoherent with what one conceives of the future, it will gravitate one towards past actions that help maintain status quo (iterational orientation). On the other hand, if a schema is coherent with one's perception of the future, one is more likely to develop new actions to seek change (projective orientation). 
In the context of technology use, the interplay of cognitive orientation and work practice, particularly in cross-boundary work contexts, makes actors more sensitive to the constraints and enablers of technology (Vaast and Walsham, 2005). We argue that both intended and unintended consequences of technology use do not occur haphazardly in crossboundary work practices; instead, they are enacted in specific moments by actors leading to a transitional cognitive orientation (Gasser, 1986; Weick, 1998). Transitional cognitive orientation operates between iterational and projective modes depending on the extent of overlapping tasks in particular intersections (Weick, 1998). For instance, when one encounters data mismatch obstructing the generation of the desired data output, one could choose to fall back on the manual approach (iterational orientation) or work around the problem (projective orientation). The latter often motivates one to experiment through trial and error leading to a series of improvisations. When improvisations stabilize over time, they become routinized allowing actors to develop new mental schemas for subsequent technology use (Feldman and Pentland, 2003: Volkoff et al., 2007).

\subsection{Task interdependency}

In cross-boundary work contexts, interdependency is not limited to tasks but also work groups where roles and task structures are intertwined (c.f. Orlikowski, 2007). Such interdependency introduces new levels of network relations that connect people both physically and virtually (Kim et al., 2012). Network combinations, including interdependency of technologies through networks of mutual platforms, lead to wider interpretations of roles, tasks, and tools influencing work practice (Markus and Robey, 1988; Suchman, 1996). Crossboundary work contexts make task interdependencies less predictable and more difficult to control. As the degree of task interdependency increases, routines will also be disrupted when actors employ different tools to relate to and accomplish the subtasks involved (Novak et al., 
2012). In doing so, actors will constantly need to make sense of the role of technology and the way it is used (Orlikowski, 2000). The process is one of technology-in-construction as actors work around IT features through different improvisation strategies such as adaptation and configuration (Vaast and Walsham, 2005). Depending on how actors view the importance of technology in their work, they may accept, avoid or work around IT when handling interdependent tasks (Kane and Labianca, 2011; Yates et al., 1999). The choice of enactment strategies could lead to both intended and unintended consequences. When task interdependencies are complex, actors could adopt a short or long-term view of technology to modify their locus of practice through variations of workarounds (Fulk, 1993).

\subsection{Technology enactment}

Technology enactment suggests how actors incorporate IT into their work practice to accomplish certain tasks at a particular point in time (Robey et al., 2002). When technology is enacted, it not only modifies task structures but also routines and roles, a process known as structuration (Poole and DeSanctis, 2004). In cross-boundary work contexts, technology enactments are largely influenced by actors' negotiation of the use and non-use of IT through a series of improvisations to stabilize the task environment (Orlikowski, 1996). In intersections of cross-boundary contexts, actors exercise technology-in-construction as transitory techniques to overcome potential obstacles in order to complete a task (Bailey et al., 2010). When multiple actors employ such techniques, they demonstrate distributed practice within and across work contexts, creating regularized patterns of enactment that make workarounds productive (Balogun and Johnson, 1999). When workarounds become productive, they create variations of improvisation that could be either adaptive or reinventive (c.f. Boudreau and Robey, 2005). We term adaptive improvisations as indirect strategies and reinventive improvisations as direct strategies. 
We expand the conceptual boundaries of improvisation by suggesting a combinative approach to workarounds (Boczkowski, 1999; Orlikowski, 1996). For instance, actors could make sense of a new technology by adapting to its environment through the use of methods they are familiar with. In this case, the protocol required to operate the new technology is not disregarded; rather, such protocol triggers particular frames of references that allow actors to undertake indirect measures to work around the requirements (c.f. Boudreau and Robey, 2005; Markus and Robey, 1988). On the other hand, when adaptation fails, actors may be required to deploy a more direct strategy by modifying the protocol of a technology, often driven by time pressure. This could involve a configuration of a technology's hardware or software to produce an emergent outcome (c.f. Robey et al., 2002). Both adaptation and configuration are variations of improvisations and workarounds, which surface differently in cross-boundary work contexts.

\subsection{Summary of literature review}

This review of related literature has led to our understanding of the importance of cognitive orientation (iterational or projective) in appreciating the agentic role of social interaction in shaping human action in technology use (Emirbayer and Mische, 1998). The review also points to how cross-boundary work contexts can facilitate the interplay of cognitive orientation and human action in enacting existing contingencies (Argote and Spektor-Miron, 2011). These contexts allow the multiplicity of roles, tasks, and IT tools to co-evolve to produce emergent enactment patterns. In understanding this interaction, it is necessary to consider how task interdependency and technology complexity can influence actors' cognitive orientation and technology enactment. Cross-boundary work contexts accelerate the interplay of technology-induced constraints and opportunities helping actors negotiate their cognitive orientation and enactment patterns (Boudreau and Robey, 2005). 
Interpretation of technology in such contexts helps actors make evaluative judgment of particular workarounds to modify and sustain competing work practice.

\section{Methods}

\subsection{Research context}

INFunity is one of the major public organizations in East Malaysia providing a range of community outreach services and programs to the public. To ensure anonymity, we will not detail its professional role but briefly describe how technology is exploited in its egovernment implementation. Announcements of the e-government initiative led INFunity to primarily streamline its workflow through integrated technology systems to serve the public more efficiently. An immediate step was to educate the public on accepting technology as a tool towards communicating with INFunity to meet specific requests such as enrolment in government-initiated programs or registration for mandated services in fulfillment of State regulatory requirements. Internally, technology was introduced in stages combining hardware and software implementation to offer comprehensive intranet platforms in order to diversify work processes.

In the first five years (1997-2002), the main focus of implementation was threefold: (1) phase out one-third of manual work; (2) install and develop new IT systems; and (3) offer IT training primarily to internal employees and secondarily to customers. In the following five years (2003-2007), efforts in phasing out manual processes by another $50 \%$ continued. However, as users are more familiar with advanced computer and communication devices such as laptops and smart phones, the implementation focused on systems integration introducing more online services for the public. The subsequent five years (2008-2012) demonstrated an increase in technology involvement evident in the public's gradual optimization of e-government services. INFunity consequently shifted its focus from 
technology construction through the development of new hardware and software programs to technology restructuring through the integration of existing hardware and software programs.

\subsection{Rationale}

The study was exploratory in nature as we set out to examine the interpretation of technology enactment by understanding the structure and action of individuals. In order to fulfill our research inquiry, we adopted a case study methodology by gathering data from a variety of sources through interviews, unobtrusive observations, and archival records. According to Yin (1994, p. 130), case study is appropriate as "the investigator has little control over events, and when focus is on a contemporary phenomenon within some real-life context." In this study, we focused on the role of technology in cross-boundary work contexts to understand how individuals managed between these contexts through the use and non-use of technology. In particular, we were interested in how individuals perceived technology and task relations within and across work boundaries that ultimately influenced their technology enactment strategies. Hence, the choice of qualitative methodology suited our purpose of inquiry as we sought to gain theoretical insights into the cognitive (interpretation) and behavioral orientation (enactment) of individuals (Boudreau and Robey, 2005; Orlikowski, 1996).

\subsection{Sampling}

We employed a purposive sampling plan chosen from three employee groups at INFunity to obtain rich descriptions of their work practices (Eisenhardt, 1989). The sample consists of 36 informants representing managers (coded M1-12), general employees (coded E1-E12), and IT specialists (coded T1-T12) (see Table I). These three groups were considered as they represent managerial, operational, and technical functions respectively. 
All three groups were involved in cross-boundary work practice handling interdependent tasks across contexts such as standardization, conventionalization, and hybridization. We conducted two rounds of interviews with four months apart involving 18 informants each, six from each sample group. While we were able to establish some salient thematic patterns in the first round of interviews, we decided to establish data validation through a second round with 18 more informants to determine if variations in the interpretation of the phenomena would offer new opportunities for theorization (Patton, 2002). A second visit also allowed us to observe more of the work practice at INFunity.

\subsection{Interview protocol}

The interview protocol was developed in three stages: exploring, affirming, and refining. At the exploring stage, we drafted broad questions pertaining to the key issues on technology interpretation and enactment based on the extant literature (e.g. Boudreau and Robey, 2005; Cordella and Iannacci, 2010; Leonardi and Barley, 2010; Orlikowski, 1996). We piloted the questions through five random employees from INFunity representing the three sample groups to eliminate any potential ambiguity in the interview questions, each lasting about 45 minutes (Hussey and Hussey, 1997). At this stage, we relied on probes to elicit richer responses to give us an idea of the scope and depth of potential responses that could be expected from the main interviews. At the affirming stage, we referred back to the literature to develop more conceptually-related questions and probes that constitute the final interview protocol. At the refining stage, we presented the questions in clusters of a broadlydefined narrative to allow individual stories to unfold from specific experiences. For instance, we used the different work contexts such as standardization (complete IT use), conventionalization (zero IT use), and hybridization (partial IT use) to provide the structure 
for storytelling (Geertz, 1973). Our constant reference to the literature helped establish theoretical validity in the questions asked (Eisenhardt, 1989).

\subsection{Interviewing}

We conducted a total of 36 semi-structured interviews averagely lasting 75 minutes each. All interviews were conducted in English as we, the researchers, are not from Malaysia and are unable to speak their local language, Malay. Although the interviews were taperecorded, we did not transcribe them verbatim as it was extremely time-consuming and onerous. Instead, we stopped the tape at different points to capture emerging themes and record noteworthy quotes. We coded the interviews individually but would compare notes through in-depth conversations to reach our final empirical and theoretical observations (Sekaran, 2000). In order to ensure objectivity of our data interpretation, we triangulated our qualitative data with archival records such as minutes of meetings, internal reports, website information, and newsletters. We also observed seven meetings that discussed issues surrounding e-government implementation and visited nine work units during the two visits (Yin, 2003).

\subsection{Data analysis}

We employed an ongoing comparative technique to help us make sense of the overall data through theoretical sampling (Glaser and Strauss, 1967). In terms of coding, we employed Vivo terms or phrases used by the informants that gave rise to categories of meanings based on Miles and Huberman's (1984) categorization and thematic-identification techniques. We first coded the data using broad categories and more specific categories based on the interview questions, particularly the probes. Where there were differences between our coding results, we would have an in-depth discussion of our interpretation of the data. 
Through an iterative process of pattern matching by comparing and analyzing the coded between us, we managed to identify a number of salient themes that emerged from several specific categories (Patton, 2002). When these themes were interpreted by relating them back to the literature, we were able to develop an integrated perspective by shaping the data into a clearer set of collective responses (Krippendorf, 1980). Overall, this iterative process not only helped us to negotiate some of our differences in data interpretation but also identify and refine the conceptual patterns that sought to answer the research questions.

In particular, we were sensitive to the way interviewees responded to their experience in cross-boundary work contexts. We identified four areas where intersections of crossboundary work could reside, as represented in Figure 2. These intersections suggest a time orientation as associated with technology use in the context of e-government implementation at INFunity. For instance, in intersection A, employees would be polarized by the past and future role of technology. In intersection B, employees would demonstrate a medium to longterm view of technology use while a short to medium-term view in intersection $\mathrm{C}$.

Intersection $\mathrm{D}$ is where employees would be most likely to experience the spectrum of past, present, and future view of technology influencing their enactment strategies.

\section{Findings}

\subsection{Interpretations of technology and enactment strategies}

The introduction of technology at INFunity not only brought initial disruptions to work practice but also modified various task structures as a result of e-government implementation. These include primarily automating the submission and retrieval of information based on internet facilities to increase the efficiency of registration, application, and workflow. However, the lack of readiness of both INFunity's employees and customers has led to internal pressure to provide a better integration between technology and work 
practice. Tensions between actors' interpretation and use of technology constantly revolve around the gap created between government (represented by service provider, INFunity) and the public when conventional ways of service delivery seem to be customers' preferred choice given their lack of IT exposure. Pressures arising from the nation-wide e-government initiative ultimately push the public-sector workforce and citizens to reconsider technology as bridging the gap between government and people.

The sudden surge in e-government services has led to much resistance among employees at INFunity affecting their work practice arising from cross-boundary work contexts. In particular, the lack of organizational readiness led to an incomplete introduction of IT-led services. Since its launch in 2007, the e-government initiative has resulted in three distinct yet overlapping work contexts at INFunity: standardization where $40 \%$ of the services are completely automated; conventionalization where $30 \%$ of the services depend fully on manual work, and hybridization where $30 \%$ of the services involve both technology and manual work. Human and operational factors prevent INFunity from a complete introduction of e-government services. As an informant pointed out, "You cannot have a complete turnaround [of work practices] until you change the way you view public service." [M5] Traditionally, public service has been perceived as stable and labor intensive, and is rarely associated with innovation (Halloway et al., 1999; West, 2004). In this study, we found that different services provided by INFunity offer shifting contexts within which actors engage in technology-in-construction (Orlikowski, 1996). By technology-in-construction, we refer to how technology is incorporated into work practice based on actors' interpretation of IT and its influence on their enactment strategies.

$=====$ Take in Table II near here $====$

As most INFunity employees are required to work cross-functionally between the contexts of standardization, conventionalization, and hybridization, they view the role of 
technology as fundamentally complex because of the variety of tasks that require IT or nonIT intervention. As such, involving IT in cross-boundary work contexts has led to actors interpreting the complexity of technology in relation to task interdependency. As we probed further, we discovered that technology complexity is not merely about how it might constrain or enable work practice; rather, it is the level of interdependency between roles and tasks in fulfilling overlapping tasks that affects the way technology is interpreted. As seen in the following quotes, working in specific contexts already poses some dilemmas and challenges when it comes to technology use affecting actors' enactment strategies. The following is an example of what working in a standardization (complete IT use) context is like:

For us, the speed [of data] comes in all directions (external and internal) and we sometimes lose control of [our] work...information is transmitted and handled by different people too quickly. Some of us feel a little 'unsettled' as we are no longer involved in doing real work...the system [now] takes over to complete the job. [E12]

In a hybridization (partial IT use) or conventionalization (zero IT use) context where the use of technology is contingent upon the types of e-government services offered, actors tend to find themselves more engaged in manual work than deploying technology to modify their work practice. The following is an example of employees choosing between processing data the technology way or the status-quo (manual) way:

Some users send multiple [service] requests online and our people have to take time to sort them out. To many [users], 'submit' button is a mystery...they don't know where the data goes. Some even send both online application... and then hard copies. [M3]

Further, we found that those who demonstrate a projective cognitive orientation towards technology tend to embrace IT as a longer-term solution and express a greater willingness to integrate IT into their work practice, as reflected in the following quote:

The world is changing. If we want to change the view of public service, we must first change the way we do our jobs. A government without technology cannot connect with the rest of the world! [T8]

Actors who are positive about IT express a greater interest in reinventive improvisations trying out new configurations (direct) rather than adapting (indirect) to the existing IT 
environment. Conversely, those who are easily bogged down by "busy work rather than productive work" [E10] tend to demonstrate a transitional cognitive orientation (between iterational and projective modes) by focusing on solving existing problems rather than exploiting the full potential of IT:

Some people (customers) are generally not 'educated' to use them (services) correctly...they keep calling our hotline for help...we become busier and lose sight of what we have to do and end up going back to square one (avoiding technology). [E9]

These actors appear to adopt a shorter to medium-term appreciation of IT intervention and may express acceptance of IT use with some evidence of indirect improvisations like adaptation. Still, there are those who relish "the good old days when our jobs are simple and straightforward and customers are easy to handle" [M6] that they interpret technology as “nuisance... irrelevant... unnecessary... obstructive." [E9] These actors largely adopt an iterational cognitive orientation sending out strong avoidance signals when it comes to technology use.

We also discovered that informants' interpretation of technology at INFunity shifts between work contexts. Where the work context is distinct at a particular point in time, their sensemaking of technology will be framed within the boundary of their role and work practice in that specific context. For instance, in the context of standardization (complete IT use), actors tend to accept technology as an inescapable way of organizational life. Here, they exhibit a more future-oriented perspective of technology as it could transform work practice through ongoing "tweaking of computer programs and systems to complete different tasks." [T3] Task interdependency in this context is technology driven as it is interfaced by IT platforms that facilitate automated data interaction supported by the view that technology is not as complex as it seems. However, in the context of conventionalization (zero IT use), actors actively recall past experiences of success in handling complex and laborious tasks such as "sorting out leave forms, registration and application forms from customers and 
planning work schedules... without making any serious mistakes.” [M9] Reference to past success causes actors to avoid technology use as they view IT as interfering with what proves to be a tried-and-tested approach to productive work in the public sector of Malaysia. As found, familiar boundaries of work contexts such as conventionalization negate the relevance of technology due to its perceived complexity making the absence of IT in work practice a routine.

A more interesting context is hybridization (partial IT use) where technology is embedded within old and new work practices. This has an effect on the way actors perceive their roles and routines pertaining to the use and non-use of IT. Interpretation of technology in this context is less direct as actors consider the level of task interdependency before they decide when to accept and avoid the use of IT. Where IT intervention is needed, actors are likely to engage in indirect improvisations through adaptation (experimenting with other IT techniques) if the perceived risk of maneuvering between IT platforms or systems is low. On the other hand, a more direct improvisation strategy like configuration (manipulating existing IT features) is sought if there is a greater impact of IT on other interrelated tasks. Because hybridization is challenged by the constant negotiation between manual and automated work, there is a much more complex relationship between actors' interpretation of technology and their enactment strategies, as evident in the following quotes:

Some of us need to input data into the system... but our input is only one data source to complete the processing. The system still needs to capture historical data... The fear is who is at fault if there are problems with the final data outcome? [E4]

It is necessary to use some manual paperwork as backup in case the system fails. The combination of work may be a little complicated now but it is definitely worthwhile. Once we have test-run the system and have all our customers' records in the database, IT will make life easier for us later. [M1]

In cross-boundary contexts (see intersections A, B, C, and D in Figure 2) where the need for IT intervention is constrained by fragments of manual work, questions surrounding when and how to improvise using new IT systems or withdraw from tried-and-tested manual 
approaches confront many actors during e-government implementation at INFunity. Crossboundary work contexts certainly stretch actors' cognitive orientation as they enact technology as a situated practice where the interplay of intended and unintended consequences of IT use is determined by the way they perceive task interdependency and technology complexity in a particular moment (Balogun and Johnson, 2005; Orlikowski, 1996). Distinct work contexts such as standardization (complete IT use), conventionalization (zero IT use), and hybridization (partial IT use) tend to routinize actors' enactment strategies. However, cross-boundary work contexts lead to disruptive routines at INFunity where actors negotiate their enactment strategies by adopting variations in their cognitive orientation based on various tasks at hand (Feldman and Pentland, 2003).

In summary, interpretation of technology is influenced by both distinct and crossboundary work contexts in which technology is enacted. The intersection of work contexts increases actors' propensity to make sense of the interdependency of roles and tasks in relation to technology complexity. When the use of technology modifies their work routines, actors negotiate meanings between familiar (distinct) and unfamiliar boundaries (crossboundary) of work contexts, affecting the way technology is enacted in situated practice. Familiarity of work practice reinforces enactment patterns that are stabilized overtime as actors repeat avoidance or improvisation techniques in contexts which allow them to accomplish certain tasks despite their interdependency. In contrast, unfamiliarity of work practice resides largely in cross-boundary work contexts where actors encounter the tension of moving forward while maintaining status quo with IT as an intervening tool. Often times, it is the negotiation of iterational and projective cognitive orientation as well as acceptance, avoidance, adaptation, and configuration that creates productive tensions in disruptive routines. 


\subsection{Cross-boundary work contexts and technology enactment}

Contexts such as standardization, conventionalization, and hybridization pose challenges for many actors involved in cross-boundary work practice where the extent of technology use is irregular and context dependent. According to an informant,

Switching from complete paperwork at one point for policy-related projects to some involvement in IT for processing course registration [for customers] makes me love IT when the paperwork becomes daunting but also makes me hate IT when I face difficulty with some [software] programs. [E3]

Where contexts of technology involvement are distinct such as standardization (complete IT use) and conventionalization (zero IT use), actors' cognitive orientation towards technology use is less ambiguous. They thus frame their technology enactment strategies as either acceptance or avoidance according to the way they interpret the complexity of technology in relation to their work practice. Technology complexity is perceived by actors as "IT... messing up my job" [M8] or "making a fool of myself when I can't talk to a machine and neglect my work." [T2]

On the other hand, the context of hybridization (partial IT use) creates more variation in how actors structure their roles to complete the required tasks. Because of the constant shift in role expectation and task interdependency to juggle between what needs to be "uploaded to SAP with [the] right justification [data] input" [E6] and what needs to be "checked and verified manually with other sources based on certain data output" [M4], actors tend to translate their acceptance into more tangible outcomes if they perceive IT as playing a more urgent and critical role in interdependent tasks. They further demonstrate direct and indirect improvisation strategies through adaptation or configuration. Particularly in crossboundary work contexts where the interaction between manual and automated tasks is much more ambiguous, actors are less likely able to grasp a clearer sense of the interdependency of tasks that needs to be completed across different domains of practice. As such, informants reflected that technology is ultimately "a working tool" [E2] helping to "connect different 
pieces of work we don't really see" [M2] and "testing our learning capacity and job manageability" [T1] as "we are like 'old dogs' learning new tricks but still required to perform old tricks.” [M11]

Findings indicate that cross-boundary work contexts are often challenged by unexpected occurrences of technical glitches such as data loss or system breakdowns that affect internal workflow and external service delivery. In these contexts, actors tend to demonstrate greater resilience in handling such disruptions through improvisations by capitalizing on the interplay of technology constraints and enablers. Cross-boundary work contexts allow them to respond to urgency in more experimental ways depending on their level of acceptance or avoidance of technology. It is in these contexts that situated practice is most prevalent where technology is constantly optimized and minimized to ensure work continuity and task completion. We next describe in greater detail the four enactment strategies: acceptance, avoidance, adaptation, and configuration (see Table III).

$=====$ Take in Table III near here $====$

Acceptance. Our unobtrusive observational data reveal that under conditions of stabilized work practice, INFunity employees demonstrate a greater level of technology acceptance by constantly referring to IT manuals to guide them in accomplishing their tasks. This usually happens when actors view task interdependency and technology complexity as minimal and thus more willing to explore the world of IT. This is particularly the case for those with little IT background where they associate simple user guides as a direct way of integrating technology into their work practice, as expressed by an informant:

Creating an EG (e-government) application is like learning to drive a car. Problems like data loss, viruses and errors are like the car getting stuck in mud. What do we do? We will first investigate the car engine and try to figure things out on our own. It's the same when using IT. [E12]

The above example illustrates the potential constraints of technology which in turn offer learning opportunities for actors to explore and enable the use of technology in more 
spontaneous ways. Simply, the constraints of having to follow a user guide systematically to perform a series of tasks allow them to structure their learning around particular IT systems. Also, the constraints of unexpected glitches provide them the opportunity to go to the basics by reworking the steps in order to complete specific tasks.

The move towards a "high-tech working environment" [M6] in order to "show [that] the government is progressing with time" [T10] provides a more macro context to help actors conceptualize technology as a "future tool for [organizational] success!" [M7] Consequently, both internal and external pressures for change have motivated actors to adopt a longer-term perspective of technology through its intended use. However, in contexts where technology is not completely involved such as hybridization (partial IT use) and conventionalization (zero IT use), actors negotiate their work practice by adopting a shorter to medium-term perspective of technology. This is where the comfort level supported by past practice has reduced their immediate connection with technology to the extent that "we prefer to drive old cars (c.f. manual work) as the engines are much more lasting" [M10] and "we can't handle the speed of new cars (c.f. technology-driven work)!” [E5]

Avoidance. With pressure arising from overlapping work contexts, it is expected that INFunity's employees continue to upgrade their IT skills but at the same time preserve the value of the manual work to satisfy particular customer needs. Cross-boundary work contexts blur the relationship between task boundaries and hence actors are more likely to lose control of how tasks are interrelated. Further, when actors view technology as interfering with their work or hindering their progress, they tend to demonstrate resistance to technology use resulting in avoidance. This is particularly the case for employees who have been at INFunity for a much longer period and prefer to uphold the civil service mode of (manual) operation to safeguard their task boundaries (Halloway et al., 1999). The following is a characteristic sentiment of technology avoidance: 
They can't teach 'old dogs' new tricks! We are dealing with change here and then come this EG (e-government) thing. We don't want to be blamed for doing things wrong or messing things up. I have skills that are tried and tested... the good old ways of doing things. [M11]

The above example illustrates the rejection of technology at the outset as actors demonstrate an inward-looking perspective of their own capability. Further, some informants questioned the relevance of certain sophisticated IT design and features to their work practice. Those who avoid technology tend to view it as a complex intervention tool disrupting task relations and complicating work practice. In such a situation, actors are more prone to doubting the reliability and constraints technology poses in the long run. Hence, they prefer to celebrate conventionalized work by focusing on the merits of direct human intervention through manual work. After all, "we are providing a service to our customers and machines can't replace this interaction!"” [T5]

IT avoidance has further led to an inequitable distribution of tasks across contexts. Complex technology-driven tasks often land on the desk of those who are more IT savvy and willing to explore new applications. To a large extent, IT avoidance can create ripple effects as some actors may influence others against using technology intensifying status quo (manual work) with technology perceived as "a white elephant on display...looking pretty but does not appeal to all users." [T7] Our findings further reveal that the dilemma in technology enactment is not merely an outright behavioral rejection but rather an iterational cognitive orientation, suggesting that if actors perceive technology as an obstacle rather than an enabler, they are more likely to choose avoidance. It is one's cognitive orientation that influences one's choice of enactment strategy. Logbooks documenting customer complaints related to e-government services indicate that most errors were due to negligence that led to data mismatch rather than a lack of individual competence. As a manager reflected, "we tried to trace back to the people who committed the errors and found out that...negative employees make more mistakes than others." [M12] Such is an example of how an interational cognitive 
orientation could quickly disconnect technology from work as actors seek predictable patterns of work practice without the interference of IT.

Adaptation. Actors who adopt a broader perspective of work practice tend to view technology as contributing towards workflow transparency and improving the quality of work life. Some of them demonstrate a fundamental curiosity to question their work practice as a result of technology ambivalence occurring in cross-boundary work contexts. For instance, a technical glitch in a standardization context (complete IT use) is interpreted differently than a similar glitch in a hybridization context (partial IT use). The latter presents actors with an opportunity for direct manual intervention eliminating the need for indirect technology improvisation. However, when confronted by time pressure to complete easily-identifiable interdependent tasks across contexts, actors tend to employ indirect improvisation strategies through adaptation where they draw on familiar technologies to complement their tasks at hand rather than falling back on manual intervention. In this situation, actors experiment through complementary IT systems and programs without being bound by specific IT protocols (Boudreau and Robey, 2005). Adaptation strategies, also referred to as indirect workarounds, contribute to cross-boundary work practice where successful IT experimentation in standardization (complete IT use) could be further adapted for refinement in hybridization (partial IT use) and vice versa. Indirect workarounds may complement or contradict each other in cross-boundary work contexts. However, they lead to instances of situated practice that are distributed across contexts (Brown et al., 1989; Vaast and Walsham, 2005). For instance, an informant commented that "when a system fails, we immediately use another [similar] system and figure out a way to back the data up.” [T4]

Time pressure largely prevents actors from being trapped in avoidance for too long as they are required to ensure that interdependent tasks are given due attention through some form of IT intervention. As a result, we observed that cross-boundary work contexts in fact 
allow IT enthusiasts to convert IT resistors to be more active in experimentation, as suggested by an informant:

Textboxes in certain systems are designed differently, either there's word limit or some don't support certain symbols like asterisks or percentage signs...data turn out gibberish. Worse still, some textboxes don't allow run-on text. Text must fit nicely in each line or it will be chopped off. Sometimes I get frustrated, but when I see others figuring out a way to 'fool' the system, I join in the fun by inputting different data to look for loopholes and 'twist' the system. [E8]

We also found that constraints posed by technology have not completely deterred actors from abandoning particular systems. Instead, cross-boundary work contexts provide the impetus for actors to turn these constraints into opportunities for further experimentation by exploiting other indirect technology interfaces or email to adapt to their solutions. Adaptation subsequently becomes a routinized practice and actors begin to view task interdependency as less multilayered and resource boundaries more defined. For instance, using a different software program in another system to feed data into a designated system has helped some actors to accomplish certain unique tasks. Adaptation of this nature sustains specific work practice even in cross-boundary work contexts.

Configuration. Actors demonstrate more direct improvisation strategies through configuration when adaptation fails particularly in situations of high task interdependency. Direct workarounds such as configuration are applied when actors are confronted by multiple subtasks that are intertwined in manual and automated processes, more so in cross-boundary contexts. When actors view technology as a direct intervention tool in simplifying task complexity, they are more likely to modify their roles from mere users to quasi-designers. This is when they attempt to "play around with functions to produce new results." [E11] Configuration happens when adaptation is inadequate or causes more complications to existing tasks than anticipated. More importantly, task interdependency in cross-boundary work contexts provides the impetus for actors to look "inside the machine and see what is wrong rather than passing the bug to someone else." [T12] In such a situation, actors are 
more likely to co-investigate particular problems with technical experts to work around the affected systems to develop solutions. This process, identified as configuration, involves reprogramming the already built-in software to create new functions without tempering with the hardware. Reprogramming often leads to structural changes to data input and output. According to an informant, "reconfiguring the features is to increase IT capacity [in order] to do better work for us.” [E7]

At times, cross-boundary contexts complicate task boundaries making task interdependency difficult to discern, preventing actors from employing indirect workarounds such as adaptation. Such contexts often require "an immediate 'dive in'....to search for the cracks" [E5] allowing actors to discover underlying issues which would not have otherwise been detected through adaptation. Configuration techniques such as reprogramming or restructuring program logics essentially operate through a reductionist approach to technology enactment as "we manipulate some features by entering dummy codes to see if the system responds with alternative source codes." [T9] The following is an exemplification:

Our challenge is to make sense of the online data from surveys, registrations and applications. In order to 'clean' our data, we alter the logic of data input to filter it into different categories based on keywords. We create other logics to allow us to merge or sort data based on our requirements to feed into other systems. [M7]

In the above example, actors expanded the capacity of technology by directly working around the input requirements to "distract the system." [T11] By the altering the program logics to satisfy different sources of data input, actors are able to work backwards based on their earlier understanding and expectation of the desired data output. In other words, "If data from one system is messy, mess gets fed into another system to produce more mess." [E6] In the end, not only will technology (dumbly) organize and manage the "messed up" data, "human effort will be futile as well." [T4] As a direct improvisation strategy, configuration seeks to work around the "mess" by helping particular systems handle and make sense of the data to deliver outputs that could be integrated into cross-boundary work contexts. 
Interplay of enactment strategies. Cross-boundary work contexts (see intersections A, $\mathrm{B}, \mathrm{C}$ and $\mathrm{D}$ in Figure 2) provide the synergy for actors to both challenge and negotiate the interplay of four distinct enactment strategies such as acceptance, avoidance, adaptation, and configuration. As found, it is at these cross-boundary intersections that actors demonstrate more emergent enactment strategies through situated practice. For instance, "we get all excited when our own experiments work...like playing with dummy codes or doing some reprograming...suddenly we become more confident to use some strange system." [T11] This is when actors begin to accept IT as the ideal state for the public service at INFunity (projective cognitive orientation) while appreciating status quo (iterational cognitive orientation) as necessary for "the IT dummies (both employees and customers) to survive." [M3] However, when task interdependency becomes even more ambivalent in crossboundary work contexts, actors demonstrate frequent negotiation of past, present, and future work practice by adopting a transitional cognitive orientation (between iterational and projective modes). It is through such interplay that “we can't be passive about IT as our mistakes (as a result of IT use) could help other people see the [same] problem differently." [E8] Simply put, cross-boundary work contexts inadvertently promote a dynamic interplay of enactment strategies as actors know just when 'to dance around or plunge in to 'rewire' those IT ‘circuits' (program logics).” [T2]

In summary, cross-boundary work contexts at INFunity offer both opportunities and challenges. While standardization (complete IT use) and conventionalization (zero IT use) present a polarity in work practice, hybridization (partial IT use) converges the practice contexts by allowing actors to evaluate task interdependency and technology complexity in modifying their enactment strategies to shape their work practice. It is at the intersections of cross-boundary contexts that provide the impetus for actors to negotiate their cognitive orientations towards technology use thereby influencing their enactment strategies. Such 
intersections create the dynamics for actors to manage between standardization, conventionalization, and hybridization that allow actors to accept, avoid, and experiment both direct and indirect IT improvisation strategies leading to instances of situated practice.

\section{Discussion}

This study extends the conversation on human agency and technology enactment in the context of e-government implementation (Boudreau and Robey, 2005; Orlikowski and Scott, 2008). It offers further insight into how cross-boundary work contexts influence actors' interpretation and enactment of technology based on their cognitive orientation and response to the task environment (Feldman and Orlikowski, 2011). In particular, we discovered that both task interdependency and technology complexity influence actors' interpretation of technology and selection of enactment strategies in cross-boundary work contexts (Levina and Vaast, 2006). On the one hand, task interdependency provides a deeper understanding of how work practice is constituted where roles and tools come into play (Argote and SpektorMiron, 2011. On the other hand, technology complexity is determined by how IT intervention could potentially complicate or disrupt task relationships making work practice unpredictable (Bailey et al., 2010). Taken together, this study extends current understanding of how context shapes the use of technology in work practice through the interplay of roles, tasks, and tools (Volkoff et al., 2007). Such interplay both disrupts and recreates routines allowing emerging work practice to stabilize over time through the negotiation of enactment strategies involving indirect and direct improvisations (Novak et al., 2012). More specifically, cross-boundary work contexts offer disruptive routines and productive tensions, leading to a dynamic interplay of acceptance, avoidance, adaptation, and configuration of technology, as illustrated in Figure 3. 


\subsection{Cross-boundary work practice through technology use}

This study extends Leonardi and Barley's (2010) call for a deeper understanding of what technology allows and does not allow organizations to do. We found that crossboundary work contexts bring out the opportunities and constraints of technology much more emergently than individual contexts such as standardization (complete IT use), conventionalization (zero IT use), and hybridization (partial IT use). During cross-boundary work practice, actors are more sensitive towards network and task structures by evaluating technology complexity and task interdependency before formulating their enactment strategies (c.f. Robey and Sahay, 1996). When actors fail to decipher the boundaries between work contexts, they are more likely to develop direct and indirect improvisation strategies to modify their roles and task structures through technology use (Bailey et al., 2010). In such situations, actors draw heavily on their frames of references based on past and perceived experience to develop their enactment strategies. In other words, their cognitive orientation shifts more dynamically when work boundaries intersect, affecting their sensemaking of roles, tasks, and tools (c.f. Walsham, 2002). For instance, employees at INFunity regard technology as a "working tool...rather than a political or diagnostic tool" [T11] to achieve the objective of e-government services as both a governmental and organizational reform (Cordella and Iannacci, 2010). The view of technology as a "working tool" suggests that it shapes the context from which work practice is constantly interpreted. While current research emphasizes human agency in relation to technology use in contexts of change (e.g. Balogun and Johnson, 2005; Leonardi and Barley, 2008; Orlikowski and Scott, 2008), few studies have examined the influence of cross-boundary work contexts on the interpretation and enactment of technology (e.g. Levina and Vaast, 2006).

Our study suggests that both context and urgency not only affect situated enactment strategies but also cause actors to experience productive tensions in their cognitive 
orientations, particularly at various intersections of cross-boundary work contexts (OwenSmith and Powell, 2004). For instance, actors could adopt an iterational cognitive orientation preferring to maintain status quo by privileging conventionalized work but at the same time adopt a longer-term perspective of their work practice (projective cognitive orientation) by improvising through technology use (c.f. Boczkowski, 1999; Weick, 1998). The constant negotiation between modes of cognitive orientation therefore reshapes their loci of practice. This finding extends current understanding of situated practice or technology-in-construction as it introduces cross-boundary work contexts as facilitating the interplay of context and cognitive orientation, and its influence on technology enactment (c.f. Boudreau and Robey, 2005; Edmondson et al., 2001; Orlikowski, 2000).

The metaphor, "working tool", speaks more volume than meets the eye at INFunity. In cross-boundary work contexts, technology serves as an interpretive tool that creates different variations of task interdependency. For instance, e-government services have reduced the need for ongoing face-to-face interaction and dialogue with customers. Instead, the "language" of communication is largely represented by codes, data, text, and program logics. As most informants noted, "even customers become an electronic form of reality!" [E12] Current literature on the role of technology in work organizations does not emphasize how actors make sense of their interdependent roles and tasks as well as disruptive routines when organizing cross-boundary work practices (e.g. Orlikowski, 2007; Volkoff et al., 2007). By examining work practice between and across contexts at INFunity, we were able to understand how actors make sense of the role of technology and its impact on interdependent tasks. More importantly, we were able to gain some insight into their cognitive frameworks that ultimately determine their enactment strategies (c.f. Boudreau and Robey, 2005).

\subsection{Technology enactment in cross-boundary work contexts}


Examining how technology is interpreted in cross-boundary work contexts helped us gain insight into another dimension of workarounds. Rather than merely recognizing the intended and unintended consequences of technology use, we discovered that different modes of cognitive orientation could lead to actors' active (acceptance) or passive (avoidance) enactment patterns. We further identified workarounds as operating at two levels, namely indirect (adaptation) and direct (configuration) improvisations (c.f. Leonardi and Barley, 2008). Particularly in cross-boundary contexts, it is the interplay of enactment strategies that shapes specific locus of practice. We next discuss each enactment strategy in detail. Acceptance. Current literature does not consider acceptance as a technology enactment strategy but rather an outcome of an intended technology use (e.g. Balogun and Johnson, 2005; Robey et al., 2002). Instead, we found that acceptance of technology is an active response and a precursor to more concrete enactment outcomes. Acceptance first occurs when actors preliminarily assess their task environment seeking an understanding of how tasks are interrelated and what tools can help reinforce interdependent task completions (Emirbayer and Mische, 1998; Gasser, 1986). In independent contexts such as standardization (complete IT use), technology acceptance is not only governed by the inevitable need for use but also by the absence of the need for use in conventionalization (zero IT use). In the latter context, acceptance is influenced by a projective cognitive orientation where technology is "to give life to the company's future." [M8] In other words, the non-use of technology in conventionalization does not negate its relevance in other work contexts; rather, acceptance of technology in a manual work context helps actors visualize the "protocol of IT" [T5] for cross-boundary work practice (c.f. Levina and Vaast, 2006). When hybridization (partial IT use) occurs, acceptance of technology could lead to both intended (following protocol) and unintended consequences (challenging protocol) as actors negotiate the use and non-use of IT to make sense of a new context. When actors move into the cross-boundary zones (e.g. A, B, 
$\mathrm{C}$ or D in Figure 2), their acceptance may be challenged to develop further enactment strategies to either support or negate their cognitive orientation towards IT use. This also suggests that technology acceptance does not lead to a rejection of manual work but rather allows actors to understand the relationship between task interdependency and technology complexity better to develop appropriate enactment strategies that enable cross-boundary work practice (c.f. Bailey et al., 2010).

Avoidance. Current perspective of technology avoidance or enactment inertia examines technology use as contributing to emotional stress if IT is perceived to have a negative impact on task structures (e.g. Boudreau and Robey, 2005; Kane and Labianca, 2011). Instead, our study suggests that avoidance is a passive enactment strategy rather than a psychological mechanism that is applied to prevent the occurrence of undesirable consequences (c.f. Edmondson et al., 2001). Our findings further suggest that avoidance is a precursor to actors accepting opportunities for technology improvisations where crossboundary work practice is concerned. Actors realize that complete avoidance of technology in one context may have an impact on another as it affects task interdependency and other concurrent cross-boundary work practices. Actors also recognize that persistent avoidance not only does not minimize disruptive routines but creates more abstract understanding of competing routines affecting their performance (Feldman and Pentland, 2003). In crossboundary work contexts, avoidance can therefore affect structure and action in relation to technology use in disruptive routines (Novak et al., 2012). As such, avoidance provides the psychological transition for actors to realign their cognitive orientation towards technology use often resulting in unintended consequences through improvisation (Leonardi and Barley, 2008). For instance, when an informant had to transition between the context of hybridization (partial IT use) and standardization (complete IT use), he was "reluctant to carry some IT errors over... but, I started to play around with the [IT] functions of another system and got 
the data output I wanted.” [E12] This example alludes to Boudreau and Robey's (2005) reference of productive interpretation resulting from inertia of enactment. We extend this perspective by suggesting that transitional cognitive orientation, demonstrated through the interplay of iterational and projective modes, creates productive tensions that allow actors to disengage from their inertia to improvise in order to sustain cross-boundary work practice (c.f. Volkoff et al., 2007).

Adaptation. Current research suggests workarounds as an unintended consequence of technology use which results in a series of improvisations, similar to technology-inconstruction, that is, how technology is used emergently in ongoing practice (e.g. Boudreau and Robey, 2005; Leonardi and Barley, 2010; Orlikowski and Barley, 2001). Our study offers another dimension of workarounds as operating at two levels, namely indirect (adaptation) and direct (configuration) improvisations. Adaptation occurs when actors perceive technology as a complex but maneuverable tool that can help them make subtle connections between interdependent tasks. Such improvisation strategy surfaces more spontaneously in cross-boundary work contexts where actors negotiate between variations in IT use. In other words, adaptation occurs when actors perceive technology as complementing rather than contradicting cross-boundary tasks. IT complementariness further provides the platform for actors to improvise by exploiting alternative systems thereby increasing their confidence and risk aversion towards cross-use of IT (Miner et al., 2001). A sentiment expressed by an informant suggests "crisscrossing between SAP and Oracle (different software programs) to explore common features... helps me to get an urgent ERP (enterprise resource planning) request going." [M2] This is an example of an indirect improvisation where all that is required is a subtle shift in the combination of techniques to accomplish particular tasks. Cross-boundary work contexts promote adaptive improvisations through the bridging of common IT functions in specific computer systems to satisfy ambivalent interdependent 
tasks. Adaptation also surfaces as a situated practice occurring in particular moments of intervention in cross-boundary intersections (c.f. Orlikowski, 1996). This observation of improvisation extends current understanding of the peripheral characteristics of workarounds by emphasizing its centrality as a precursor to configuration, a more direct enactment strategy (Vaast and Walsham, 2009). Current literature also does not emphasize the reciprocity of workaround techniques (e.g. Balogun and Johnson, 2005; Orlikowski, 2000). However, our study suggests that reciprocity is a critical enabler for bridging cross-boundary work contexts through indirect and direct improvisation strategies (c.f. Own-Smith and Powell, 2004).

Configuration. Our findings indicate that when adaptation fails, a more direct approach to improvisation which we term configuration will be applied. Configuration occurs when the complexity of task interdependencies requires actors to "rewire the machine by looking into [its] internal muscles." [T9] As a direct workaround strategy (e.g. Gasser, 1986; Suchman, 1996), configuration offers more specific "massage of IT logics" that offers a different dimension to current understanding of reinvention (Boudreau and Robey, 2005). Configuration requires a structural modification of program logics (operating procedures) to compensate for certain IT constraints. This entails a greater socialization of technology enactments by integrating experiences to provide "internal solutions... based on [the] direct intervention of our IT support group." [M1] In other words, configuration offers a more direct and structured approach than a circular approach (work-around) to resolving technology issues (c.f. Leonardi and Barley, 2010; Orlikowski and Barley, 2001). Configuration therefore goes beyond the use of dummy data or replicated codes to alter the structure of technology; instead, it involves reprogramming such that "it's like you try to turn an ordinary Samsung [smartphone] into an iPhone!" [T7] In doing so, actors draw on a variety of experiences and sources of IT expertise to reconcile the intended and unintended consequences to identify gaps that could be bridged through configurative redesign of 
programs. Particularly in cross-boundary work contexts where social interaction becomes more robust, configuration is often the result of collaborative efforts between actors including IT specialists. Direct users recognize their lack of expertise and therefore consider a wider network of expertise to reconfigure certain software programs to satisfy interdependent task contingencies (c.f. Markus, 2004; Robey et al., 2002). Cross-boundary work contexts also provide the opportunity for collaborative configuration of both social and IT network giving new meanings to reciprocity in technology enactment. Reciprocity is not only seen between workarounds or improvisations but also between actors in reinforcing human agency. Configuration therefore provides coherence to both structure and action between technology and human agency (Robey and Sahay, 1996).

In summary, our findings suggest that enactment strategies of technology surface more emergently in cross-boundary than independent work contexts. It is the interplay of contexts such as standardization, conventionalization, and hybridization at intersections of cross-boundary work practices that creates productive tensions as actors negotiate between modes of cognitive orientation to develop situated enactment patterns. The study extends the technology enactment perspective in relation to human agency (e.g. Boudreau and Robey, 2005; Markus and Robey, 1988) where temporal agentic orientations constructed by crossboundary work contexts give new meanings to structures of action (Emirbayer and Mische, 1998). In turn, the role of technology gives rise to disruptive routines giving structures of action the variations that constitute situated practice (Edmondson et al., 2001). Our study also illuminates how productive tensions arising from the interplay of opportunities and constraints of technology use contribute to actors' deeper understanding of their roles, tasks, and tools (Orlikowski and Scott, 2008). Cross-boundary work contexts not only help actors realize the potential of their enactment strategies but also help make them coherent to satisfy complex interdependent tasks (Levina and Vaast, 2006). 


\section{Implications, Limitations, and Future Research}

Understanding how employees frame their cognitive orientations and develop technology enactment strategies in cross-boundary work contexts at INFunity has led to some implications for practice. Early interventions could involve examining how and why employees accept or avoid technology as part of their work practice. Once preliminary attitudinal patterns of technology use can be identified, it would be useful to further determine how employees switch between technology use and non-use in hybridized work practice. As task interdependency becomes more complex in cross-boundary work contexts particularly during e-government implementation, it is important that organizations modify their task environment to streamline tasks that could be executed through compatible modes of IT intervention (Thompson, 1967). Team learning is of particular importance to crossboundary work practice in public organizations like INFunity where exposure to IT is limited. Organizations could ensure better team support to capitalize on the robust social interaction in cross-boundary work contexts to develop greater synergy in technology improvisations. Lessons learned from specific improvisation experiences can be shared and applied in contexts where intersections between technology acceptance, avoidance, adaptation, and configuration come into play (Miner et al., 2001). It is at these intersections that collaborative efforts influence one another's cognitive orientations turning an iterational mode (avoidance) to a projective mode (acceptance). Through cognitive transitions, employees can then further develop improvisation strategies to sustain their performance in cross-boundary work practice.

The study is not without its limitations. The lack of opportunity to gather longitudinal data prevented us from gaining further insight into how technology enactment strategies might play out as standardized (complete IT use) work practices increase overtime at 
INFunity. The study was also constrained by the number and variety of employees we could possibly interview due to limitations imposed by our role as external researchers. Public organizations usually observe strict guidelines with regard to the types and amount of data researchers could potentially gather onsite. Still, we were able to conduct our research through a variety of methods with meaningful data that helped us in our conceptualization of technology interpretation and enactment.

To advance this study, future researchers could examine the relationship between the four technology enactment strategies in other cross-boundary work contexts, perhaps in a more heterogeneous work environment involving full-time and contractual employees, vendors, and customers. This would offer deeper insight into the cognitive orientation of actors in work contexts where ownership of tasks and sense of belonging are different (c.f. Bailey et al., 2010; Orlikowski and Scott, 2008). In particular, how actors negotiate between enactment strategies in high task-interdependent contexts would be worth exploring. When task interdependency becomes increasingly complex in cross-boundary work contexts, it challenges actors' responses to technology opportunities and constraints. Future research could explore how actors compensate for such constraints by accepting what technology may not let users do as they organize their actions around intended and unintended consequences (Leonardi and Barley, 2010). In other words, bridging mechanisms to help actors shift between enactment strategies in cross-boundary work contexts would be worth exploring. From an e-government perspective, future studies could take into consideration the internal and external influences of technology based on changes in public service and policy (c.f. Cordella and Iannaci, 2010; Hayes, 2008).

\section{References}


Abdul Karim, M. R., and Mohd Khalid, N. (2003), E-government in Malaysia, Publications Sdn. Bhd, Pelanduk Selangor, DE.

Argote, L. (1999), Organizational Learning: Creating, Retaining, and Transferring Knowledge, Kluwer, Norwell, MA.

Argote L. and Spektor-Miron, E. (2011), “Organizational learning: From experience to knowledge”, Organization Science, Vol. 22, No. 5, pp. 1123-1137.

Bailey, D. E., Leonardi, P. M. and Chong, J. (2010), "Minding the gaps: Understanding technology interdependence and coordination in knowledge work", Organization Science, Vol. 21, No. 3, pp. 713-730.

Balogun, J. and Johnson, G. (2005), "From intended strategies to unintended outcomes: The impact of change recipient sensemaking”, Organization Studies, Vol. 26, No. 1, pp. $1573-1601$.

Bechky, B. A. (2003), "Sharing meaning across occupational communities: The transformation of understanding on a production floor", Organization Science, Vol. 14 No. 3, pp. 312-330.

Boczkowski, P. J. (1999), "Mutual shaping of users and technologies in a national virtual Community", Journal of Communication, Vol. 49, No. 2, pp. 86-108.

Boudreau, M. and Robey, D. (2005), “Enacting integrated information technology: A human agency perspective", Organization Science, Vol. 16, No. 1, pp. 3-18.

Brown, J. S., Collins, A. and Duguid, P. (1989), "Situated cognition and the culture of learning", Educational Researcher, Vol. 18, No. 1, pp. 32-42.

Button, G. (1993), "The curious case of the vanishing technology”, in Button, G. (Ed.), Technology in Working Order: Studies of Work, Interaction and Technology, Routledge, London, UK, pp. 10-28. 
Chen, Y., Chen, H. M., Ching, R. H. K. and Huang, W. W. (2007), "Electronic Government implementation: A comparison between developed and developing countries", International Journal of Electronic Government Research, Vol. 3, No. 2, pp. 45-61.

Cordella, A. and Iannacci, F. (2010), "Information systems in the public sector: The egovernment enactment framework", Journal of Strategic Information Systems, Vol. 19 No. 1, pp. 52-66.

Deng, H. (2008), “Towards objective benchmarking of electronic government: An intercountry analysis", Transforming Government: People, Process and Policy, Vol. 2, No. 3, pp. $162-176$.

Edmondson, A. C., Bohmer, R. M. and Pisano, G. P. (2001), “Disrupted routines: Team learning and new technology implementation in hospitals", Administrative Science Quarterly, Vol. 46 No. 4, pp. 685-716.

Eisenhardt, K. (1989), "Building theories from case study research”, Academy of Management Review, Vol. 14, No. 4, pp. 532-550.

Emirbayer, M. and Mische, A. (1998), “What is Agency?”, American Journal of Sociology, Vol. 103, No. 4, pp. 962-1023.

Fang, X., Hu, J. P., Li, Z. and Tsai, W. (2013), "Predicting adoption probabilities in social network", Information Systems Research, Vol. 24, No. 1, pp. 128-145.

Feldman, M. S. and Orlikowski, W. J. (2011), “Theorizing practice and practicing theory”, Organization Science, Vol. 22, No. 5, pp. 1240-1253.

Feldman, M. S. and Pentland, B. T. (2003), "Reconceptualizing organizational routines as a source of flexibility and change", Administrative Science Quarterly, Vol. 48, No. 1, pp. 94-118.

Fountain, J. E. (2001), Building the Virtual State. Information Technology and Institutional Change, Brookings Institution Press, Washington, DC. 
Fulk, J. (1993), "Social construction of communication technology”, Academy of Management Journal, Vol. 36, No. 5, pp. 921-951.

Gasser, L. (1986), “The integration of computing and routine work”, ACM Transactions on Information Systems, Vol. 4, No. 3, pp. 205-225.

Geertz, C. (1973). The interpretation of cultures: Selected essays, Basic Books, New York, NY.

Glaser, B. and Strauss, A. (1967), Discovering grounded theory, Aldine, Chicago, IL.

Halloway, J., Francis, G. and Hinton, M. (1999), “A vehicle for change? A case study of performance improvement in the 'new' public sector", International Journal of Public Sector Management, Vol. 12, No. 4, pp. 351-365.

Hayes, N. (2008), "Institutionalizing change in a high-technology optronics company: The role of information and communication technologies", Human Relations, Vol. 6, No. 2, pp. 243-269.

Hussey, J. and Hussey, R. (1997), Business Research, Palgrave, New York, NY.

Jaeger, P. T. and Thompson, K. M. (2003), "E-government around the world: Lessons, challenges, and future directions", Government Information Quarterly, Vol. 20, No. 1, pp. 389-394.

Jarzabkowski, P. (2005), Strategy as practice: An activity based approach, Sage, London.

Kane, G. C. and Labianca, G. J. (2011), "IS Avoidance in health-care groups: A multilevel investigation", Information Systems Research, Vol. 22, No. 3, pp. 504-522.

Kellog, K. C., Orlikowski, W. J. and Yates, J. (2006), "Life in the trading zone: Structuring coordination across boundaries in postbureaucratic organizations", Organization Science, Vol. 17, No. 1, pp. 22-44. 
Kim, H., Chan, H. C. and Kankanhalli, A. (2012), "What motivates people to purchase digital items on virtual community websites? The desire for online self presentation", Information Systems Research, Vol. 23, No. 4, pp. 1232-1245.

Kling, R. and Scacchi, W. (1982), The web of computing: Computer technology as social organization, Public Policy Research Organization, Irvine, CA.

Krippendorff, K. (1980), Content Analysis: An Introduction to its Methodology, Sage, London.

Leonardi, P. M. and Barley, S. R. (2008), "Materiality and change: Challenges to building better theory about technology and organizing", Information and Organization, Vol. 18, No. 3, pp. 159-176.

Leonardi, P. M. and Barley, S. R. (2010), "What's under construction here? Social action, materiality, and power in constructivitist studies of technology and organizing”, Academy of Management Annals, Vol. 4, No. 1, pp. 1-51.

Levina, N. and Vaast, E. (2006). "Turning a community into a market: A practice perspective on IT use in boundary-spanning”, Journal of Management Information Systems, Vol. 22, No. 4, pp. 13-38.

Levitt, B. and March, J. B. (1988), “Organizational learning”, Annual Review Sociology, Vol. 14 No. 1, pp. 319-340.

Lin, L. H. (2011), “Electronic human resource management and organizational innovation: The roles of information technology and virtual organizational structure", International Journal of Human Resource Management, Vol. 22, No. 2, pp. 235-257.

Markus, M. L. (2004), “Technochange management: Using IT to drive organizational change”, Journal Information Technology, Vol. 19, No. 1, pp. 3-19. 
Markus, M. L. and Robey, D. (1988), “Information technology and organizational change: Causal structure in theory and research", Management Science, Vol. 34, No. 5, pp. 583598.

Miles, M. B. and Huberman, A. M. (1994), Qualitative Data Analysis, Sage, Beverly Hills, CA.

Miner, A. S., Bassoff, P. and Moorman, C. (2001), “Organizational improvisation and learning: A field study", Administrative Science Quarterly, Vol. 46, No. 2, pp. 304-337.

Marrone, J. A., Tesluk, P. E. and Carson, J. B. (2007), “A multilevel investigation of antecedents and consequences of team member boundary-spanning behavior", Academy of Management Journal, Vol. 50, No. 6, pp. 1423-1439.

Nasim, S., and Sushil (2010), "Managing continuity and change: A new approach for strategizing in e-government", Transforming Government: People, Process and Policy, Vol. 4, No. 4, pp. 338-364.

Novak, L., Brooks. J. Gadd, C., Anders, S. and Lorenzi, N. (2012), "Mediating the intersections of organizational routines during the introduction of a health IT system", European Journal of Information Systems, Vol. 21, No. 5, pp. 552-569.

Orlikowski, W. J. (1992), “The duality of technology: Rethinking the concept of technology in organizations", Organization Science, Vol. 3, No. 3, pp. 398-427.

Orlikowski, W. J. (1996), “Improvising organizational transformation over time: A situated change perspective. Information Systems Research, Vol. 7, No. 1, pp. 63-92.

Orlikowski, W. J. (2000), “Using technology and constituting structures: A practice lens for studying technology in organizations", Organization Science, Vol. 11, No. 4, pp. 404428.

Orlikowski, W. J. (2007), “Sociomaterial practices: Exploring technology at work", Organization Studies, Vol. 28, No. 9, pp. 1435-1448. 
Orlikowski, W. J. and Barley, S. R. (2001), “Technology and institutions: What can research on information technology and research on organizations learn from each other?" MIS Quarterly, Vol. 25, No. 2, pp. 145-165.

Orkikowski, W. J. and Iacono, S. (2001), “Research commentary: Desperately seeking the 'IT' in IT research - A call to theorizing the IT artifact", Information Systems Research, Vol. 12, No. 2, pp. 121-134.

Orlikowski, W. J. and Scott, S. V. (2008), "Sociomateriality: Challenging the separation of technology, work and organization”, Academy of Management Annals, Vol. 2, No. 1, pp. $433-474$.

Owen-Smith, J. and Powell, W. W. (2004), "Knowledge networks as channels and conduits: The effects of spillovers in the Boston biotechnology community", Organization Science, Vol. 15, No. 1, pp. 5-21.

Patton, M. Q. (2002), Qualitative research and evaluation methods, $3^{\text {rd }}$ ed., Sage, Thousand Oaks, CA.

Piszczek, M. M. and Berg, P. (2014), “Expanding the boundaries of boundary theory: Regulative institutions and work-family role management", Human Relations, Vol. 67, No. 12, pp. 1491-1512.

Poole, M.S. and DeSanctis, G. (2004), "Structuration theory in information systems research: Methods and controversies, in Whitman, M.E. and Woszczynski, A.B. (Eds.), The Handbook of Information Systems Research, Idea Group Publishing, Harrisburg, PA, pp. $206-249$.

Preston, D. S. and Karahanna, E. (2009), “Antecedents of IS strategic alignment: A nomological network", Information Systems Research, Vol. 20, No. 2, pp. 159-179. 
Robey, D. and Sahay, S. (1996), “Transforming work through information technology: A comparative case study of geographic information systems in county government", Information Systems Research, Vol. 7, No. 1, pp. 93-110.

Robey, D., Ross, J. W. and Boudreau, M. (2002), "Learning to implement enterprise systems: An exploratory study of the dialectics of change", Journal of Management Information Systems, Vol. 19, No. 1, pp. 17-46.

Sekaran, U. (2000), Research Methods for Business, John Wiley \& Sons, New York, NY.

Siddiquee, N. A. (2008), "E-government and innovations in service delivery: The Malaysian experience", International Journal of Public Administration, Vol. 31, No. 7, pp. 797815.

Suchman, L. A. (1996), “Supporting articulation work”, in Kling, R. (Ed.), Computerization and Controversy, $2^{\text {nd }}$ ed., Academic Press, San Diego, CA, pp. 407-423.

Schultze, U. and Orlikowski, W. J. (2004), “A practice perspective on technology-mediated network relations: The use of internet-based self-serve technologies", Information Systems Research, Vol. 15, No. 1, pp. 87-106.

Thompson, J. D. (1967), Organizations in Action, McGraw-Hill, New York, NY.

Vaast, E. and Walsham, G. (2005), "Representations and actions: The transformation of work practices with IT use", Information and Organization, Vol. 15, No. 1, pp. 65-89.

Vaast, E. and Walsham, G. (2009), “Trans-situated learning: Supporting a network of practice with an information infrastructure", Information Systems Research. Vol. 20, No. 4, pp. 547-564.

Volkoff, O., Strong, D. M. and Elmes, M. B. (2007). “Technological embeddedness and organizational change”, Organization Science, Vol. 18, No. 5, pp. 832-848.

Walsham, G. (2002), "Cross-cultural software production and use: A structuration analysis", MIS Quarterly, Vol. 26, No. 4, pp. 359-380. 
Weick, K. E. (1998), “Improvisation as a mindset for organizational analysis”, Organization Science, Vol. 9, No. 5, pp. 543-555.

West, D. M. (2004), “E-government and the transformation of service delivery and citizen attitudes", Public Administration Review, Vol. 64, No. 1, pp. 15-27.

Yates, J., Orlikowski, W. J. and Okamura, K. (1999), “Explicit and implicit structuring of genres in electronic communication: Reinforcement and change of social interaction”, Organization Science, Vol. 10, No. 1, pp. 83-103.

Yeo, R. K. (2009), “Electronic government as a strategic intervention in organizational change processes", Journal of Change Management, Vol. 9, No. 3, pp. 271-304.

Yin, R. K. (2003). Case study research: Design and methods ( $3^{\text {rd }}$ Ed.), Sage, Thousand Oaks, CA.

Zammuto, R. F., Griffith, T. L., Majchrzak, A., Dougherty, D. J. and Faraj, S. (2007).

"Information technology and the changing fabric of organization", Organization Science, Vol. 18, No. 5, pp. 749-762. 
Figure 1: Conceptual Themes

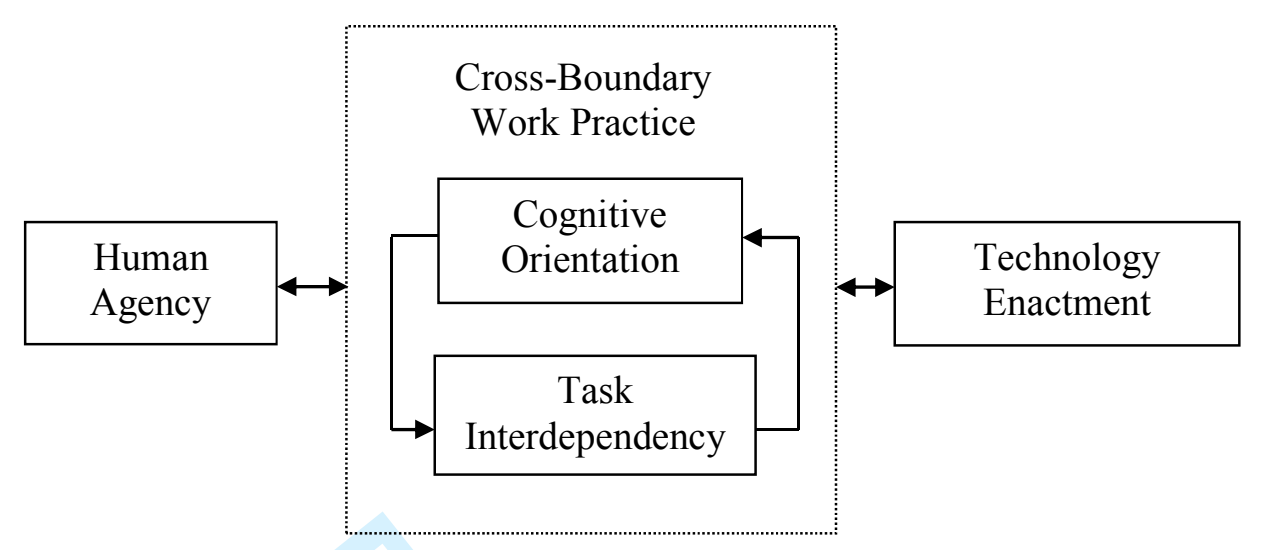

Figure 2: Cross-Boundary Work Contexts

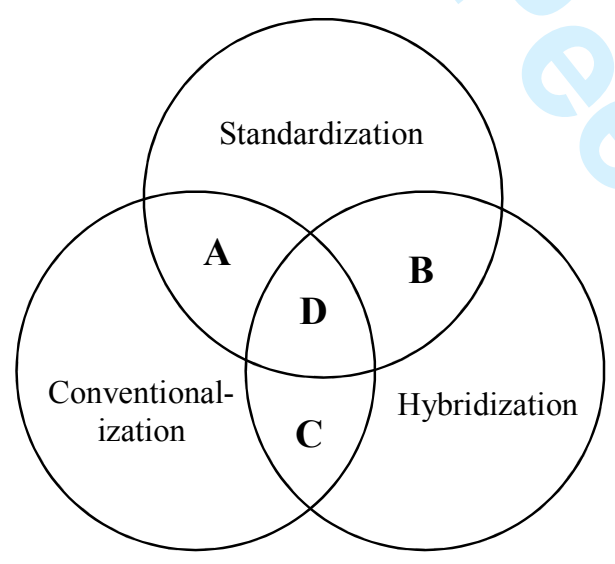


1

2

3

4

5

6

7

8

9

10

11

12

13

14

15

16

17

18

19

20

21

22

23

24

25

26

27

28

29

30

31

32

33

34

35

36

37

38

39

40

41

42

43

44

45

46

47

48

49

50

51

52

53

54

55

56

57

58

59

60

Figure 3: Enactment strategies of technology

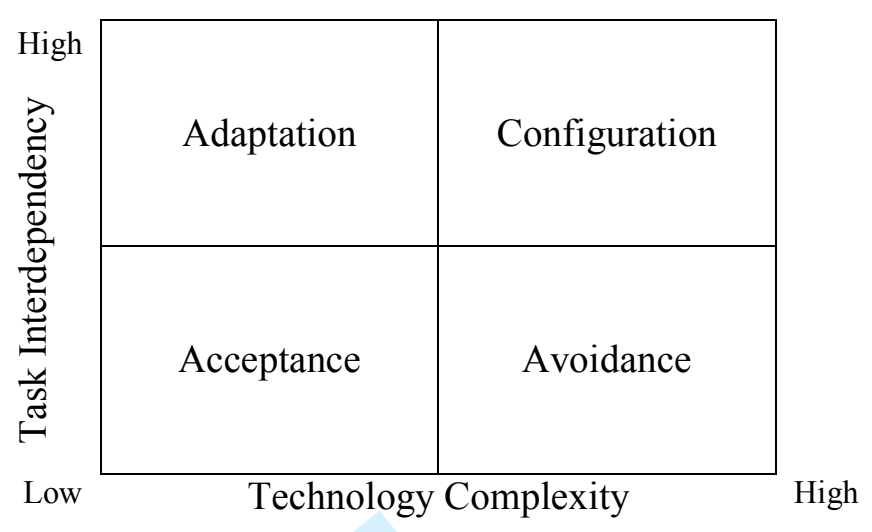


Information Technology \& People

Page 52 of 54

\begin{tabular}{l}
1 \\
2 \\
3 \\
4 \\
5 \\
6 \\
7 \\
8 \\
9 \\
10 \\
11 \\
12 \\
13 \\
14 \\
15 \\
16 \\
17 \\
18 \\
19 \\
20 \\
21 \\
22 \\
23 \\
24 \\
25 \\
26 \\
27 \\
28 \\
29 \\
30 \\
31 \\
32 \\
33 \\
34 \\
35 \\
36 \\
37 \\
38 \\
39 \\
40 \\
41 \\
42 \\
43 \\
44 \\
45 \\
46 \\
47 \\
48 \\
49 \\
50 \\
51 \\
52 \\
53 \\
54 \\
55 \\
56 \\
57 \\
59 \\
\hline
\end{tabular}

Table I: Sampling plan

\begin{tabular}{|c|c|c|c|c|}
\hline Subjects & $\begin{array}{c}\text { Interviewee } \\
\text { Codes }\end{array}$ & $\begin{array}{c}\text { First Interview } \\
(\boldsymbol{N})\end{array}$ & $\begin{array}{c}\text { Second Interview* } \\
(\boldsymbol{N})\end{array}$ & Total \\
\hline Managers & M1-M12 & 5 & 7 & 12 \\
\hline Employees & E1-E12 & 6 & 6 & 12 \\
\hline IT Specialists & T1-T12 & 7 & 5 & 12 \\
\hline & Subtotal & 18 & 18 & 36 \\
\hline
\end{tabular}

Note: The two interviews were conducted four months apart. 
Table II: Influence of technology interpretations on enactment strategies

\begin{tabular}{|l|l|l|}
\hline $\begin{array}{l}\text { Enactment } \\
\text { Strategies }\end{array}$ & Interpretations & Illustrative Quotes \\
\hline $\begin{array}{l}\text { Acceptance: } \\
\text { Following } \\
\text { protocol }\end{array}$ & $\begin{array}{l}\text { Technology } \\
\text { complexity: Low } \\
\text { Task interdependency: } \\
\text { Low (Fundamental) }\end{array}$ & $\begin{array}{l}\text { "I know we can't run away from IT because it's } \\
\text { a global thing. I think we can learn and use [it] to } \\
\text { do our work but it takes time. I don't think we } \\
\text { have a choice." [E5] }\end{array}$ \\
\hline $\begin{array}{l}\text { Avoidance: } \\
\text { Maintaining } \\
\text { status quo }\end{array}$ & $\begin{array}{l}\text { Technology } \\
\text { complexity: High }\end{array}$ & $\begin{array}{l}\text { "I am not a friend of IT and this e-government } \\
\text { program sometimes makes our life complicated } \\
\text { here. I try to concentrate on things that don't } \\
\text { require IT... If I can help, I'll let other people } \\
\text { handle the IT part and I just make decisions." } \\
\text { [M7] }\end{array}$ \\
\hline $\begin{array}{l}\text { Adaptation: } \\
\text { Experimenting } \\
\text { with other IT } \\
\text { techniques }\end{array}$ & $\begin{array}{l}\text { Technology } \\
\text { complexity: Low }\end{array}$ & $\begin{array}{l}\text { "I have my own tricks to 'beat' the system by } \\
\text { inputting data into other [familiar] systems to see } \\
\text { if it works first. Problem is, once you input } \\
\text { something and make a mistake [in the actual } \\
\text { system], the data becomes haywired. My backup } \\
\text { file is my saving grace." [M4] }\end{array}$ \\
\hline $\begin{array}{l}\text { Configuration: } \\
\text { Manipulating } \\
\text { existing IT } \\
\text { features }\end{array}$ & $\begin{array}{l}\text { Technology } \\
\text { complexity: High }\end{array}$ & $\begin{array}{l}\text { "People misuse the online job application by } \\
\text { entering 'junk'... We now use it as a pre- } \\
\text { screening [tool] by creating rigid textboxes and } \\
\text { [document] attachments. We had to rewrite the } \\
\text { [software] program And wasted some time but it } \\
\text { was worth it." [T6] }\end{array}$ \\
\hline
\end{tabular}


Table III: Influence of work contexts on technology enactment strategies

\begin{tabular}{|c|c|c|c|c|}
\hline Context & Acceptance & Avoidance & Adaptation & Configuration \\
\hline $\begin{array}{l}\text { Standardization } \\
\text { (Complete IT use in } \\
40 \% \text { of services) }\end{array}$ & $\begin{array}{l}\text { One adopts a long-term } \\
\text { view of IT and rationalizes } \\
\text { its inevitable role in work } \\
\text { practices. }\end{array}$ & $\begin{array}{l}\text { One focuses on constraints } \\
\text { than opportunities of IT but } \\
\text { potential negative } \\
\text { consequences could become } \\
\text { opportunities in other work } \\
\text { contexts. }\end{array}$ & $\begin{array}{l}\text { One draws on existing } \\
\text { boundaries of IT familiarity as } \\
\text { a strategy for meeting task } \\
\text { requirements in response to } \\
\text { pressure for change. }\end{array}$ & $\begin{array}{l}\text { One takes experimentation } \\
\text { outside one's IT comfort } \\
\text { zone when adaptation } \\
\text { strategy fails to create } \\
\text { alternative technology- } \\
\text { related work practices. }\end{array}$ \\
\hline $\begin{array}{l}\text { Hybridization } \\
\text { (Partial IT use in } \\
30 \% \text { of services) }\end{array}$ & $\begin{array}{l}\text { One adopts a short-to- } \\
\text { medium-term view of IT } \\
\text { expecting to use it only } \\
\text { when required. }\end{array}$ & $\begin{array}{l}\text { One focuses on merits of } \\
\text { manual work as one has direct } \\
\text { control over one's tasks but } \\
\text { indirectly makes them more } \\
\text { conscious of IT use } \\
\text { minimizing potential errors. }\end{array}$ & $\begin{array}{l}\text { One extends search into } \\
\text { complementary features of } \\
\text { other systems to reduce task } \\
\text { complexity combining human } \\
\text { and technology intervention. }\end{array}$ & $\begin{array}{l}\text { One investigates the internal } \\
\text { functions of a specific } \\
\text { system when adaptation } \\
\text { creates more IT problems in } \\
\text { other unrelated tasks. }\end{array}$ \\
\hline $\begin{array}{l}\text { Conventionalization } \\
\text { (Zero IT use in } 30 \% \\
\text { of services) }\end{array}$ & $\begin{array}{l}\text { One accepts importance of } \\
\text { IT but recognizes its role as } \\
\text { context dependent for } \\
\text { satisfying work input and } \\
\text { output. }\end{array}$ & $\begin{array}{l}\text { One recognizes success of } \\
\text { direct human involvement in } \\
\text { manual work practices but } \\
\text { implicitly hopes to achieve } \\
\text { the same benefit in an IT- } \\
\text { related work context. }\end{array}$ & $\begin{array}{l}\text { Complete manual work } \\
\text { eliminates temporary } \\
\text { relationship with IT but } \\
\text { indirectly promotes conceptual } \\
\text { adaptation in preparation for a } \\
\text { different work context. }\end{array}$ & $\begin{array}{l}\text { Complete manual work } \\
\text { motivates one to juxtapose } \\
\text { between being backward and } \\
\text { forward looking to help one } \\
\text { make sense of the role of } \\
\text { technology in cross- } \\
\text { boundary work practices. }\end{array}$ \\
\hline
\end{tabular}

